\title{
A COVID-19 screening tool for oncology telephone triage
}

\section{Emmika Elkin $^{1} \cdot$ Carol Viele $^{2} \cdot$ Karen Schumacher $^{2} \cdot$ Maureen Boberg $^{1} \cdot$ Mari Cunningham ${ }^{1} \cdot$ Lauren Liu $^{1}$. Christine Miaskowski ${ }^{1,2,3,4}$ [D}

Received: 19 June 2020 / Accepted: 20 August 2020 / Published online: 28 August 2020

(C) Springer-Verlag GmbH Germany, part of Springer Nature 2020

\begin{abstract}
Purpose Symptoms associated with COVID-19 infection have made the assessment and triage of cancer patients extremely complicated. The purpose of this paper is to describe the development and implementation of a COVID-19 screening tool for oncology telephone triage.

Methods An Ambulatory Oncology Clinical Nurse Educator and three faculty members worked on the development of an oncology specific triage tool based on the challenges that oncology nurses were having with the generic COVID triage tool. A thorough search of the published literature, as well as pertinent websites, verified that no screening tool for oncology patients was available.

Results The screening tool met a number of essential criteria: (1) simple and easy to use, (2) included the most common signs and symptoms as knowledge of COVID-19 infection changed, (3) was congruent with the overall screening procedures of the medical center, (4) included questions about risk factors for and environmental exposures related to COVID-19, and (5) assessed patient's current cancer history and treatment status. Over a period of 3 weeks, the content and specific questions on the tool were modified based on information obtained from a variety of sources and feedback from the triage nurses.

Conclusion Within 1 month, the tool was developed and implemented in clinical practice. Oncology clinicians can modify this tool to triage patients as well as to screen patients in a variety of outpatient settings (e.g., chemotherapy infusion units, radiation therapy departments). The tool will require updates and modifications based on available resources and individual health care organizations' policies and procedures.
\end{abstract}

Keywords COVID-19 $\cdot$ Cancer $\cdot$ Telephone triage $\cdot$ Screening $\cdot$ Symptoms

\section{Introduction}

Since the emergence of the novel coronavirus SARS-CoV-2 (COVID-19) in December 2019, in Wuhan, China [1], the care of oncology patients has changed dramatically. While data on the occurrence of COVID-19 in cancer patients is

Emmika Elkin

emmika.elkin@ucsf.edu

1 Department of Nursing, Helen Diller Family Comprehensive Cancer Center, University of California, San Francisco, CA 94143, USA

2 Department of Physiological Nursing, School of Nursing, University of California, San Francisco, CA, USA

3 Department of Anesthesia and Perioperative Care, School of Medicine, University of California, San Francisco, CA, USA

4 Pain and Addiction Research Center, University of California, San Francisco, CA, USA limited, in a study from China, the prevalence rate was $1.0 \%$ among 1590 confirmed cases [2]. Of note, in their analysis, after adjusting for age, sex, and comorbidities, a cancer diagnosis was associated with the highest risk of developing severe adverse events (i.e., need for mechanical ventilation, death). In subsequent studies of adverse events, patients with cancer who contracted COVID-19 were 2 to 3 times more likely to have higher rates of severe/critical symptoms [3] and higher rates of intubation [4].

The need to treat and at the same time protect oncology patients during the COVID-19 pandemic has escalated the need for accurate telephone triage. This dual need is particularly important for the care of oncology patients who are receiving treatment because the symptoms associated with COVID-19 and those associated with radiation therapy, chemotherapy, and/or targeted therapy can overlap (Table 1). In an effort to provide effective emergency management for lifethreatening complications of COVID-19 and/or cancer treatments, provide appropriate self-care and symptom 
Table 1 Overlap between symptoms of COVID-19, allergies, flu, and cancer and its treatments

\begin{tabular}{|c|c|c|c|c|}
\hline Symptoms & $\begin{array}{l}\text { COVID- } \\
19\end{array}$ & Allergies & Flu & Cancer and its treatments \\
\hline Cough & - & & - & - \\
\hline Fever & - & & - & - \\
\hline Chills & - & & - & - \\
\hline Repeated shaking chills & & & & - \\
\hline Muscle pain & - & & घ & - \\
\hline Shortness of breath or difficulty breathing & - & & & - \\
\hline Sore throat & - & & घ & - \\
\hline New loss of taste or smell & - & & & - \\
\hline Persistent pain or chest pressure & - & & & - \\
\hline Headache & - & & & - \\
\hline Nausea & - & & - & - \\
\hline Vomiting & - & & - & - \\
\hline Diarrhea & - & & - & - \\
\hline New confusion & - & & & - \\
\hline Inability to wake or stay awake & - & & & - \\
\hline Bluish lips or face & - & & & - \\
\hline Red or painful eyes & - & - & & - \\
\hline Sneezing & & - & & \\
\hline Itchy eyes and nose & & - & & \\
\hline Runny or stuffy nose & & - & & \\
\hline
\end{tabular}

management for either condition, and/or initiate appropriate referrals for emergency care or routine management without increasing unnecessary risk of viral exposure, oncology nurses need to use all of their interviewing skills to obtain the necessary information to make appropriate triage decisions.

The first known case of community spread of COVID-19 in the USA was reported in Northern California on February 28, 2020 [5]. With this announcement, both primary care and specialty practices began to prepare for an increase in patients in both ambulatory and inpatient settings. As noted by Hickey and Newton [6], a nursing assessment of oncology patients can be quite complicated. While several tools were developed to guide self-triage [7] or health care system's triage of patients with potential COVID-19 infection [8], none of these tools were specific for oncology patients. The purpose of this paper is to describe the development and implementation of a practical COVID-19 screening tool for oncology telephone triage.

\section{Methods}

\section{Setting}

The University of California, San Francisco (UCSF) Helen Diller Family Comprehensive Cancer Center (HDFCCC) was designated as a Comprehensive Cancer Center by the National Cancer Institute in December 1999. Approximately 6500 adults and children are newly diagnosed with cancer each year at HDFCCC. Outpatient visits total over 100,000 per year. In terms of the COVID epidemic, in February 2020, UCSF was one of the first health care systems in the USA to care for patients with COVID-19 [9]. On March 17, a "shelter in place order" went into effect in San Francisco and five other Bay Area counties [10].

\section{Telephone screening procedures}

With the issuance of the "shelter in place order," while chemotherapy and radiation therapy treatments continued, nonurgent cancer surgeries were postponed and the initiation of new cancer treatments were determined on an individual basis. At the same time, UCSF developed a generic COVID-19 telephone screening tool for use in all outpatient clinics

(https://4c27ta1wi0ea2ypdxh4fepue-wpengine.netdna-ssl. com/wp-content/uploads/2020/05/Algorithm-forAmbulatory-Remote-Triage-for-Patients-with-RespiratoryIllness.pdf).

This screening tool changed on an ongoing basis as the epidemic evolved and salient signs and symptoms associated with COVID-19 emerged. As the telephone triage nurses in the various oncology clinics at UCSF began to use this tool, it was readily apparent that this generic tool was not adequate to 
Table 2 (continued)

\section{Work Up for Escalating Care}

- Is the quality of your cough changing? (YES/NO)

- Are you having any of the following respiratory symptoms?

$\Gamma$ Shortness of breath
$\Gamma$ Change in sputum consistency or color
$Г$ Change in chronic respiratory symptoms
$Г$ Decreased activity tolerance
$\Gamma$ Difficulty breathing while laying flat
$\Gamma$ Only able to speak short sentences
$Г$ Wheezing
$\Gamma \star * *$

- Have the color of your lips or face changed? (i.e. bluish lips and/or ashen face) (YES/NO)

- Do you have a pulse oximeter? (YES/NO)

$\circ$ (If yes) What was your last measured your pulse ox? ${ }^{* * *}$

- What date and time? ${ }^{* * *}$

$\circ$ Is that normal for you? (YES/NO)

- Have you recently lost consciousness? (YES/NO)

\section{Disposition}

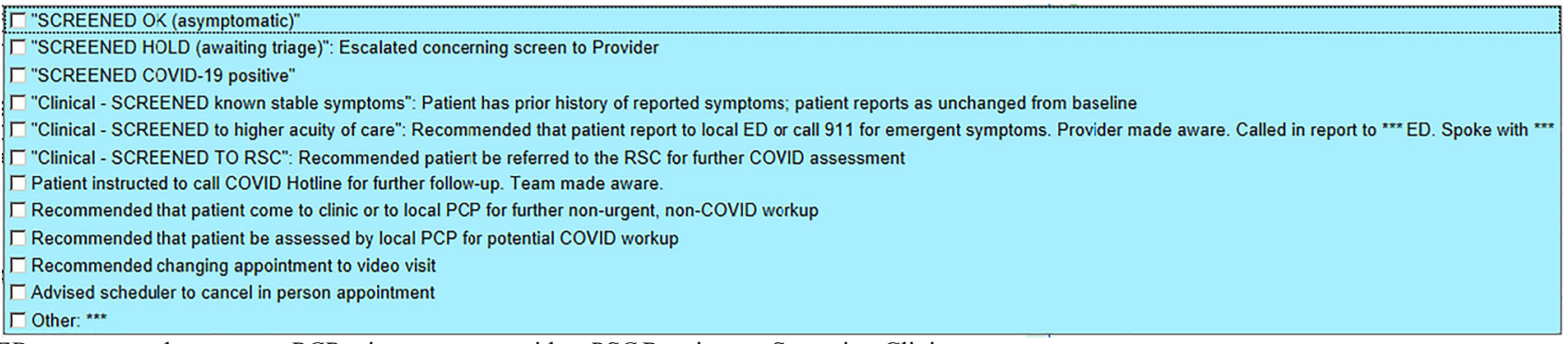

$E D$ emergency department, $P C P$ primary care provider, $R S C$ Respiratory Screening Clinic

distinguish between COVID-19 and cancer treatment-related symptoms and to assist nurses to make triage decisions for oncology patients.

\section{Tool development}

The Ambulatory Oncology Clinical Nurse Educator for the HDFCCC (EE) and three faculty members in the UCSF School of Nursing (CV, KS, CM) met on April 20, 2020, to discuss the challenges the oncology nurses were having with using the generic telephone triage tool with oncology patients. A thorough search of the published literature, as well as pertinent websites (e.g., Centers for Disease Control and Prevention, Oncology Nursing Society, American Society of Clinical Oncology, National Comprehensive Cancer Network), verified that no screening tool for oncology patients was available. Therefore, we began to work on the development of a COVID-19 screening tool for oncology telephone triage.

The goal of this work was to develop a screening tool that was (1) simple and easy to use; (2) included the most common signs and symptoms as knowledge of COVID-19 infection changed; (3) was congruent with the overall screening procedures of the UCSF medical center; (4) included questions about COVID-19 testing and medical care; (5) included questions about risk factors for and environmental exposures related to COVID-19; (6) assessed patient's current cancer history, treatment status, and co-occurring medical conditions; and (7) assessed for changes in patients' cough and escalation in the severity of respiratory symptoms. With the inclusion of questions on the patients' cancer history and current treatments and emphasis on asking patients whether their symptoms (which could be related to COVID-19 and/or cancer and its 
treatments), the nurses were able to make more informed triage decisions.

Over a period of 3 weeks, the content and specific questions on the tool were modified based on information obtained from a variety of sources. Information on environmental and general risks associated with COVID-19 were obtained from the Centers for Disease Control and Prevention Guidelines [11]. General clinical questions were adapted from oncology telephone triage protocols [6]. Symptom questions were developed and revised based on publications that reported the evolving symptoms of COVID-19 [12-14], as well as the team's extensive knowledge of cancer-related symptoms.

After several iterations and updates, the tool was sent to six triage nurses in different oncology specialties (e.g., urological surgical oncology, thoracic oncology, head and neck surgical oncology) for review and critique. Based on their feedback, the content of the tool was revised and updated with the latest information (Table 2).

\section{Integration and evaluation in clinical practice}

Once the final version of the screening tool was approved by nursing administration, the Ambulatory Oncology Clinical Nurse Educator (EE) worked with the Medical Center staff to create a SmartPhrase version of the screening tool that was integrated into our electronic health record from Epic Systems (Verona, WI). On May 21, 2020, 75 adult solid tumor oncology triage nurses began using the tool. Feedback from the telephone triage nurses who are using the tool on a daily basis are overwhelmingly positive (e.g., easy to use, enables the assessment of both COVID-19 and cancer-related symptoms, enables decisionmaking regarding management). Of note, the Medical Director of the UCSF Mission Bay Respiratory Screening Clinic requested that this tool be used by nurse practitioners in the Oncology Infusion Clinics. While the nurses use the screening tool primarily on the telephone, it can be used during video visits. The duration of each screening session is highly variable depending on the patient's condition and presenting symptoms.

While a formal evaluation of the responses to the screening questions and disposition status of the patients would be the optimal approach to evaluate the sensitivity and specificity of the tool in screening oncology patients during the COVID-19 pandemic, the focus of this paper is on the collaborative process that clinicians and educators used to develop this tool. In addition, given that the pandemic has not ended and oncology practices are re-opening within the context of a "new normal," we wanted to disseminate this tool for use in other oncology practices. Given the dynamic nature of this pandemic, this tool warrants ongoing modifications and evaluation. Within our health care system, with the embedded SmartPhrase lists, it is very easy to edit and modify our tool to keep it up-to-date with the latest COVID-19 screening recommendations. Other health care systems will need to modify the tool to meet their needs as well as the changing nature of the pandemic.

\section{Discussion}

As oncology practices begin re-opening in the context of a "new normal" and without treatments options or a vaccine for COVID19 , oncology nurses will continue to play a critical role in triaging patients undergoing cancer treatments to protect them from potential exposure to the virus and provide appropriate interventions to manage COVID-19 emergencies, as well as emergencies associated with cancer treatment and ongoing symptoms associated with either condition. As of June 19, 2020, only one article from an International Collaborative Group has described guidelines for the management of cancer patients during the COVID-19 pandemic [15]. As noted in these international guidelines, strategies should be implemented to maintain cancer treatment particularly for patients who are being treated with curative intent.

Given that the majority of cancer care around the world is performed in outpatient settings, the screening tool described in this paper and that is being used in the oncology infusion units at UCSF may be useful in screening patients prior to treatments in ambulatory oncology clinics, chemotherapy infusion units, and radiation therapy departments. As noted in the international guidelines [15], outpatient settings will need to put into place strict screening procedures that include a call to the patient on the day before their scheduled appointment. As noted in Table 2, screening questions should focus on new or increased severity of symptoms associated with COVID-19, environmental and behavioral risk factors, previous and ongoing cancer treatments and symptoms, and symptoms that warrant emergency treatments. While the tool is designed to facilitate patient assessments, the amount of time to complete an interview is highly variable and depends on the complexity of the patient's health status.

While symptom assessment and management is the cornerstone of oncology nursing practice, the COVID-19 pandemic poses new challenges to these assessments particularly when we cannot see and examine the patient. The use of a systematic approach to guide clinicians' assessments will assist them to differentiate among the myriad of symptoms that overlap between these two conditions as well as those associated with allergies and the flu. Given that on average oncology patients present with 10 to 15 unrelieved symptoms $[16,17]$, as well as that three out of four oncology patients have at least one chronic medical condition [18, 19], triage nurses, as well as oncology clinicians in outpatient settings, will need to refine existing tools to perform comprehensive screening assessments in as safe and efficient manner as possible. Across the globe, refinements will need to be made to the tool described in this paper to account for variations in settings of care, how screening procedures are done, and available resources for screening and triage. For example, in some settings, the integration of the tool into the patient's 
electronic health record would be ideal. However, in other settings, triage nurses will need to make written notations into the patient's medical record. The use of self-triage [7] and telephone triage tools like the one described in this paper, that are integrated into the electronic health record and enhanced with artificial intelligence algorithms, will enable the identification of high-risk patients with high sensitivity and specificity.

Authors' contributions All of the authors participated in the development and revision of the screening tool, the revisions of the paper, and the final approval of the manuscript.

Data availability Not applicable.

\section{Compliance with ethical standards}

Conflicts of interest The authors declare that they have no conflict of interest.

Ethics approval Not applicable.

Consent to participate Not applicable.

Consent for publication All authors read the final version of the paper and approved its submission for publication.

\section{References}

1. Hen N, Zhou M, Dong X, Qu J, Gong F, Han Y, Qiu Y, Wang J, Liu Y, Wei Y, Xia J, Yu T, Zhang X, Zhang L (2020) Epidemiological and clinical characteristics of 99 cases of 2019 novel coronavirus pneumonia in Wuhan, China: a descriptive study. Lancet 395(10223):507-513. https://doi.org/10.1016/ s0140-6736(20)30211-7

2. Liang W, Guan W, Chen R, Wang W, Li J, Xu K, Li C, Ai Q, Lu W, Liang H, Li S, He J (2020) Cancer patients in SARS-CoV-2 infection: a nationwide analysis in China. Lancet Oncol 21(3):335337. https://doi.org/10.1016/s1470-2045(20)30096-6

3. Dai M, Liu D, Liu M, Zhou F, Li G, Chen Z, Zhang Z, You H, Wu M, Zheng Q, Xiong Y, Xiong H, Wang C, Chen C, Xiong F, Zhang Y, Peng Y, Ge S, Zhen B, Yu T, Wang L, Wang H, Liu Y, Chen Y, Mei J, Gao X, Li Z, Gan L, He C, Li Z, Shi Y, Qi Y, Yang J, Tenen DG, Chai L, Mucci LA, Santillana M, Cai H (2020) Patients with cancer appear more vulnerable to SARS-CoV-2: a multicenter study during the COVID-19 outbreak. Cancer Discov 10(6):783791. https://doi.org/10.1158/2159-8290.Cd-20-0422

4. Miyashita H, Mikami T, Chopra N, Yamada T, Chernyavsky S, Rizk D, Cruz C (2020) Do patients with cancer have a poorer prognosis of COVID-19? An experience in New York City. Ann Oncol 31:1088. https://doi.org/10.1016/j.annonc.2020.04.006

5. Moon S (2020) The CDC has changed the criteria for testing patients with corona virus after the first case of unknown origin was confirmed. CNN. https://www.cnn.com/2020/02/27/health/uscases-coronavirus-community-transmission/index.html.

6. Hickey M, Newton S (2019) Telephone triage for oncology nurses, 3rd edn. Oncology Nursing Society, Pittsburgh

7. Judson TJ, Odisho AY, Neinstein AB, Chao J, Williams A, Miller C, Moriarty T, Gleason N, Intinarelli G, Gonzales R (2020) Rapid design and implementation of an integrated patient self-triage and self-scheduling tool for COVID-19. J Am Med Inform Assoc. 27: 860. https://doi.org/10.1093/jamia/ocaa051

8. Centers for Disease Control and Prevention (2020) Corona disease 2019 (COVID-19): symptoms \& testing 2020. https://www.cdc. gov/coronavirus/2019-ncov/symptoms-testing/index.html.

9. Allday E, Ho C (2020) Bay Area officials scramble to contain corona virus as UCSF accepts two patients. San Francisco Chronicle, https://www.sfchronicle.com/bayarea/article/U-Sofficials-take-aggressive-measures-to-15027383.php

10. Allday E (2020) Bay Area orders "shelter in place," only essential businesses open in 6 counties. 2020, https://www.sfchronicle.com/ local-politics/article/Bay-Area-must-shelter-in-place-Only15135014.php

11. Centers for Disease Control and Prevention (2020) Evaluating and testing persons for coronavirus disease 2019 (COVID-19). https:// www.cdc.gov/coronavirus/2019-nCoV/hpc/clinical-criteria.html.

12. Guan WJ, Ni ZY, Hu Y, Liang WH, Ou CQ, He JX, Liu L, Shan H, Lei CL, Hui DSC, Du B, Li LJ, Zeng G, Yuen KY, Chen RC, Tang CL, Wang T, Chen PY, Xiang J, Li SY, Wang JL, Liang ZJ, Peng YX, Wei L, Liu Y, Hu YH, Peng P, Wang JM, Liu JY, Chen Z, Li G, Zheng ZJ, Qiu SQ, Luo J, Ye CJ, Zhu SY, Zhong NS (2020) Clinical characteristics of coronavirus disease 2019 in China. N Engl J Med 382(18):1708-1720. https://doi.org/10.1056/ NEJMoa2002032

13. Ueda M, Martins R, Hendrie PC, McDonnell T, Crews JR, Wong TL, McCreery B, Jagels B, Crane A, Byrd DR, Pergam SA, Davidson NE, Liu C, Stewart FM (2020) Managing cancer care during the COVID-19 pandemic: agility and collaboration toward a common goal. J Natl Compr Canc Netw:1-4. doi:https://doi.org/ $10.6004 /$ jnccn.2020.7560

14. Yang F, Shi S, Zhu J, Shi J, Dai K, Chen X (2020) Clinical characteristics and outcomes of cancer patients with COVID-19. J Med Virol. doi:https://doi.org/10.1002/jmv.25972

15. Al-Shamsi HO, Alhazzani W, Alhuraiji A, Coomes EA, Chemaly RF, Almuhanna M, Wolff RA, Ibrahim NK, Chua MLK, Hotte SJ, Meyers BM, Elfiki T, Curigliano G, Eng C, Grothey A, Xie C (2020) A practical approach to the management of cancer patients during the novel coronavirus disease 2019 (COVID-19) pandemic: an International Collaborative Group. Oncologist. 25:e936. https:// doi.org/10.1634/theoncologist.2020-0213

16. Papachristou N, Barnaghi P, Cooper B, Kober KM, Maguire R, Paul SM, Hammer M, Wright F, Armes J, Furlong EP, McCann L, Conley YP, Patiraki E, Katsaragakis S, Levine JD, Miaskowski C (2019) Network analysis of the multidimensional symptom experience of oncology. Sci Rep 9(1):2258. https://doi.org/10.1038/ s41598-018-36973-1

17. Miaskowski C, Cooper BA, Aouizerat B, Melisko M, Chen LM, Dunn L, Hu X, Kober KM, Mastick J, Levine JD, Hammer M, Wright F, Harris J, Armes J, Furlong E, Fox P, Ream E, Maguire R, Kearney N (2017) The symptom phenotype of oncology outpatients remains relatively stable from prior to through 1 week following chemotherapy. Eur J Cancer Care (Engl) 26(3). https://doi.org/ 10.1111/ecc. 12437

18. Ritchie CS, Zhao F, Patel K, Manola J, Kvale EA, Snyder CF, Fisch MJ (2017) Association between patients' perception of the comorbidity burden and symptoms in outpatients with common solid tumors. Cancer 123(19):3835-3842. https://doi.org/10.1002/cncr.30801

19. Renzi C, Kaushal A, Emery J, Hamilton W, Neal RD, Rachet B, Rubin G, Singh H, Walter FM, de Wit NJ, Lyratzopoulos G (2019) Comorbid chronic diseases and cancer diagnosis: disease-specific effects and underlying mechanisms. Nat Rev Clin Oncol 16(12): 746-761. https://doi.org/10.1038/s41571-019-0249-6

Publisher's note Springer Nature remains neutral with regard to jurisdictional claims in published maps and institutional affiliations. 